\title{
Doce días para doce meses. De meteorología popular en la Romania'
}

\author{
JOSÉ ENRIQUe GARGALlO GIL \\ Universidad de Barcelona
}

Per a l'amic Joan Veny, 18 tardors, 66 primaveres

\section{REGENERACIÓN Y PREFIGURACIÓN DEL TIEMPO. LOS DOCE DÍAS}

En El mito del eterno retorno, Mircea Eliade ${ }^{2}$ aborda diversos ritos y creencias ancestrales, propios de pueblos de Europa y Asia, y vinculados a la regeneración del tiempo. Regeneración periódica del tiempo, en torno a la entrada del "Año Nuevo". Eterna repetición del acto cosmogónico. Inauguración de una nueva era, un nuevo año, y prefiguración del tiempo anual recién inaugurado.

Así, en el curso del ceremonial del Año Nuevo babilónico, el akitu, en cuyo marco se celebraba la llamada "fiesta de las Suertes". Durante doce días se determinaban los presagios para cada uno de los doce meses del año, lo que (en palabras de M. Eliade) "equivalía a crear los doce meses por venir" ${ }^{3}$.

1 Agradezco sugerencias, consejos y ayuda a las siguientes personas: Manuela Barros Ferreira, José-Ignacio García Armendáriz, Helena González Fernández, J. Ramón Magdalena Nom de Déu, Lola Monfort, Cleudene de Oliveira Aragão, Pilar Puig, Alejandra de Riquer, Natalia Rodríguez, Katia Sancho, João Saramago, Jaime Vándor Koppel y Joan Veny. Mención y gratitud especiales merece, por su generosa lectura del texto, la amiga Mireia Campabadal i Bertran.

2 Mircea ElIADE, El mito del eterno retorno. Arquetipos y repetición (Madrid: Alianza Editorial, 1996), pp. 53-88. Cito de la traducción espanola de Le mythe de l'éternel retour. Archétypes et répétitions (Paris: Gallimard, 1951). Y citaré en lo sucesivo la bibliografía de referencia (siempre en nota) de manera íntegra en la primera mención (como en el párrafo anterior) y abreviada en las siguientes. Para facilitar la consulta, las referencias bibliográficas abreviadas (APELLIDO(S) DE AUTOR(ES), palabra o sintagma clave del título de la obra / o bien siglas, páginas u otras indicaciones) serán remitidas sistemáticamente al número de nota (entre paréntesis o corchetes) en que se cita por primera vez la obra correspondiente: $n$. [en abreviación de nota] $+n .^{\circ}$ de nota (tal como se deja ver en la nota que sigue a ésta).

3 Eliade, El mito, p. 58 (n. 2). 
"Suertes" meteorológicas, como las que abordaremos en la presente contribución, del moderno ámbito romance. "Correspondencias cósmicas" ${ }^{4}$, como en los jours de sort del ámbito lingüístico francés (3.1,c), cada uno de los cuales gobierna simbólica y meteorológicamente su mes respectivo. A la manera de un "mini-año" que contiene el año todo. A modo de microcosmos que alberga su correspondiente macrocosmos.

Docenas de tiempo, en definitiva, que se materializan asimismo en creencias de origen ancestral, aún mantenidas en distintos lugares de Europa, computadas y presididas por doce días, allá por el Año Nuevo y en torno al solsticio de invierno 5 .

Muertos que vuelven junto a sus familias en los doce días que separan la Navidad de la Epifanía, o durante las noches correspondientes ${ }^{6}$. Seres míticos como los "kallikantzaroi" del folklore griego actual, de los que se dice que aparecen durante esos doce días (o más bien sus noches, pues andan siempre de noche), y que pasan el resto del año bajo la superficie de la tierra?. Confundidos en Macedonia con los hombres$\operatorname{lobos}^{8}$. Y semejante ciclo de los 12 días, así como la creencia en hombres-lobos se testimonian en la tradición nórdica, en Suecia y en Noruega, ya en textos del siglo XII ${ }^{9}$.

Otros doce días transcurren entre el de Santa Lucía y el de Navidad. De gran significación en el ciclo anual, la fecha de Santa Lucía, el 13 de diciembre. Asociado secularmente al solsticio de invierno, percibido sin

\footnotetext{
4 Así nombradas en Jacques Cellard / Gilbert Dubors, Dictons de la pluie et du beau temps (Paris: Éditions Belin, 1985), p. 184.

5 Doce días de "tiempo suspendido" que vendrían a corresponder, según Yvonne DE SIKE [Fêtes et croyances populaires en Europe au fil des saisons (Turin: Bordas, 1995), pp. 45-46], a la diferencia de tiempo entre el año lunar (de doce lunaciones $=354$ días) y el solar (de doce meses $=365,2422$ días). Diferencia aproximativa, en todo caso, pues el desajuste entre ambas medidas anuales, lunar y solar, está más próximo a los once días que a los doce.

6 Eliade, El mito, pp. 63, 67 (n. 2).

7 Julio Caro Baroja, “"Olentzaro”. La fiesta del solsticio de invierno en Guipúzcoa oriental y en algunas localidades de la montaña de Navarra", Revista de Dialectología $y$ Tradiciones Populares, II (1946), pp. 42-68 (y concretamente las pp. 64-65).

8 Caro Baroja, "Olentzaro", p. 66 (n. 7).

"Véase al respecto Claude Gaignebet, "El calendario de la brujería", Temas de Antropología Aragonesa (Zaragoza: Instituto Aragonés de Antropología), 5 (1995), pp. 17-29 (y concretamente las pp. 17-18). Asimismo, sobre tales creencias ligadas a los "doce días" de renovación anual, y otras similares, en diversos pueblos europeos, véase SIKE, Fêtes, pp. 45-48 (n. 5): "Les douze jours, le temps suspendu, un compromis culturel" y "Kallikantzari, faunes, ancêtres ou diablotins. Les douze jours dans les traditions helléniques".
} 
duda como el día del renacer solsticial en los últimos siglos medievales y hasta la reforma gregoriana del calendario (de 1582), retenido como el 'día de la luz' en el norte de Europa (Lysdagen en Noruega). En Hungría "se prepara durante 12 días una silla pequeña con 12 maderas diferentes de árboles" ${ }^{10}$ "silla de Lucía" desde la que en la misa del día 13 "se puede ver a todas las personas que son brujas ${ }^{11}$. Doce días, habrá que suponer, previos al trece. Lo que no concuerda con la información del diccionario académico de la lengua húngara ${ }^{12}$, que se refiere a una silla, utilizada para fines supersticiosos, y tallada día a día, desde el de Santa Lucía al de Navidad ${ }^{13}$.

Doce días en el lindero del Año Nuevo (cuando éste ya comenzaba por enero) observaban los agricultores romanos, como nos testimonia Columela, para procurarse auspicios favorables de cara al resto del año.

Durante estos días los labradores más escrupulosos se abstienen de labrar la tierra, pero de modo que el mismo día 1 de enero empiezan toda clase de trabajos para tener buenos auspicios, aplazando sólo el laboreo de la tierra hasta el día $13^{14}$.

\section{EL MARCO ROMANCE. JUSTIFICACIÓN}

Asimismo los doce días que separan Nochebuena de la Epifanía siguen siendo considerados actualmente como una prefiguración de los doce meses del año, debido a que el Año Nuevo repite el acto cosmogónico. Los campesinos de

10 Tal se lee en GAignebet, "El calendario”, p. 28 (n. 9).

"Ibidem. Y a propósito de dicha "silla de Lucía", vale la pena señalar que en húngaro lucaszék (literalmente 'silla de Lucía') presta cuerpo a un interesante fraseologismo: valóságos lucaszék, 'una verdadera silla de Lucía' (otra vez literalmente). Algo que tarda mucho en terminarse, como la obra del Escorial.

12 Magyar Értelmezó kéziszótâr (Budapest: Akadémiai Kiadó, 1982), s.v. lucaszék.

13 Compárese con lo apuntado por Sike, Fêtes, p. 43 (n. 5), a propósito del día de Santa Lucía:

On commence à confectionner la "chaise de Luce" sur laquelle monteront les jeunes filles pendant la messe de minuit et du haut de laquelle elles pourront apercevoir leur futur mari et reconnaître les sorcières.

Si bien no se especifica, es de suponer que la "misa de medianoche" mencionada se refiera a la de Nochebuena.

${ }^{14}$ Per hos quoque dies abstinent terrenis operibus religiosores agricolae, ita tamen ut ipsis calen. Ianuariis auspicandi causa omne genus operis instaurent, ceterum differant terrenam molitionem usque in proximas idus. (Columela, De re rustica, XI, 2, 98). Cito de la traducción castellana coordinada por A. Holgado Redondo (ed.), L. J. M. Columela, De los trabajos del campo (Madrid: Ministerio de Agricultura, Pesca y Alimentación / Siglo XXI de España Editores, 1988), p. 249. 
toda Europa no tienen otras razones cuando determinan el tiempo de cada mes y su ración de lluvia por medio de los signos meteorológicos de esos doce días ${ }^{15}$.

A tenor de lo expresado en esta cita, la predicción de doce días para doce meses, una de las manifestaciones perviventes de aquel mito del eterno retorno, se mantendría actualmente y en todo el continente europeo. Desde la India hasta las Islas Británicas, según otra autora ${ }^{16}$.

Pues bien, aun dando crédito a tales noticias, de vasta implicación territorial, entiendo que mi aporte, más particular y preciso, del ámbito romance puede ser de algún provecho.

De mi espigueo por fuentes escritas, de mi rebuscar en testimonios orales, por comunicaciones personales y por otras vías insospechadas, he ido obteniendo una notable cosecha de noticias de este singular método de predicción, antiquísimo al parecer. Por más que mi propósito no era el de llegar a las raíces más hondas de tal modo de previsión meteorológica, me ha parecido oportuno atender, en el apartado precedente, a lo que sin duda son manifestaciones múltiples de un fondo común, la consideración (mágica, ritual, práctica, ¿lúdica?) de doce unidades de tiempo en el renovarse de los años.

En los apartados siguientes, pretendo catalogar esta mi cosecha romance. Todos los testimonios que reúno, pueden tenerse por modernos, del siglo XIX a esta parte. Con la salvedad de la noticia que extraigo de la obra del agrónomo catalán Miquel Agustí (de 1617) [3.1 (d)]. Nada he hallado del ámbito rumano, que en ésta como en otras facetas de la cultura popular se me muestra apartadizo con respecto al resto de la Romania europea. De esta Romania territorialmente continua, y de las islas mediterráneas adyacentes (Baleares, Sicilia), he allegado la mayor parte de los datos. Y algo, bastante poco, de la Romania nueva americana (Brasil y algún país de habla española), y del archipiélago de las Azores. Fuera de lo románico, presento alguna información (de territorio vasco, de la Suiza germánica) que considero de interés por su comunidad cultural con el entorno romance, con la Romania periférica.

Ahora bien, la modernidad o la actualidad de estos datos habrá que entenderla de un modo bastante laxo, con un alcance variable. Algunas fuentes de las que bebo son bien recientes, de esta misma década. Otras son decimonónicas. En más de un caso los datos aportados, si bien son de los últimos años, no responden tanto a una práctica activa cuanto al

15 Eliade, El mito, pp. 65-66 (n. 2).

16 SIKE, Fêtes, p. 46 (n. 5). 
recuerdo de lo creído o practicado por generaciones anteriores. Algo así como lo que se percibe en algunas obras de la dialectología tradicional (monografías, atlas lingüísticos) de este siglo, que proporcionan a menudo hechos dialectales caducos o semiolvidados ya en la contemporaneidad de tales obras, por su tendencia a retratar lo arcaico. Algo así he detectado en testimonios orales, como en la calendas y recalendas de $\mathrm{mi}$ propio lugar natal (Puebla de Arenoso; 3.1,e), que ya mis padres y mi abuela apenas recordaban, y que he podido certificar gracias a la confirmación de algún otro informante nativo, de bastante edad y dedicado aún a las tareas agrícolas.

Cuestión primordial es a qué doce días y a qué disposición de los doce meses corresponden las creencias expresadas por cada testimonio, en lo que hay no poca variedad. Por otra parte, las noticias de tales predicciones docenarias a menudo no van acompañadas de una denominación explícita. Y cuando sí la tienen, ésta se suele presentar en forma de substantivos en plural (o sintagmas nominales con un núcleo en plural), conforme a la índole colectiva y contable del referente, que sólo en raros casos recibe nombre de substantivo en singular.

Informaciones nominadas (las más) e innominadas (las menos) que catalogo en el apartado tercero por correspondencias de días y meses, y ocasionalmente de otras unidades de tiempo (mañanas y tardes, quincenas y lunas). El cuarto atiende a los nombres (etimologías, motivaciones, derivación y composición). Sigue y remata un apartado de "palabras y cosas", de doce indicios materiales vinculados a una noche.

\section{LA PREVISIÓN METEOROLÓGICA: DE DOCE DÍAS PARA DOCE MESES}

¿Qué doce días? ¿Qué disposición para los doce meses correspondientes? La cita que encabeza el apartado anterior bien pudiera hacernos creer en doce días precisos (entre Navidad y Reyes) como vaticinio colectivo para el año recién iniciado. Los datos romances de mi aportación apuntan, en cambio, a una interesante variedad de cómputos y correspondencias entre días y meses. Ni siquiera entre Navidad y Reyes hay unanimidad en el recuento. En éste quedará incluido el día de la Epifanía (como duodécimo) siempre que no se cuente con el de Navidad. En cambio, si el día de Navidad entra en el cómputo (como primero), el de Reyes, no (como decimotercio). Ni más ni menos que por esa doble posibilidad de recuento (inclusivo o exclusivo) en algunas lenguas del área germánica la Epifanía se nombra con denominaciones basadas en el concepto 
de 'duodécimo' (en inglés Twelfth Night) o el más común de 'decimotercio' (entre otros, el sueco trettondagen y el bajo alemán y neerlandés dertiendag) ${ }^{17}$.

Por ese mismo razonamiento, tampoco es unánime el cómputo que proporcionan algunos refranes del calendario entre Santa Lucía (13 de diciembre) y Navidad. Y se contradicen al respecto los siguientes, del gallego (por una parte) y del catalán (por otra) ${ }^{18}$.

De San Andrés [30 de noviembre] a Santa Lucía, trece días día por día; e diste día a Nadal, trece dias nun egoal

De Santa Lucia a Nadal, doce dias botan os que saben contar (doucia de noites van)

De Santa Llúcia a Nadal, dotze dies de cabal

Santa Llicia de la Bisbal, tretze dies abans de Nadal ${ }^{19}$

Y es que, cuando el cálculo de los doce días va de Santa Lucía a Navidad (una de las variantes del cómputo mejor secundadas en mi cosecha romance), o de Navidad a Reyes (con notable representación románica, también), lo más corriente es que el día de Navidad quede excluido del recuento. Del 13 al 24 de diciembre, y del 26 de diciembre al 6 de enero, pues. Pero hay otras variantes en la disposición de los doce días, como veremos.

De la diversidad de correspondencias, sólo en el ámbito hispánico, puede dar una idea la segunda acepción que el diccionario académico asigna a cabañuela (en su forma plural cabañuelas):

Cálculo que, observando las variaciones atmosféricas en los doce, dieciocho o veinticuatro primeros días de enero o de agosto, forma el vulgo para pronosticar el tiempo que ha de hacer durante cada uno de los meses del mismo año o del siguiente ${ }^{20}$.

17 Carlo Tagliavini, Storia di parole pagane e cristiane attraverso $i$ tempi (Brescia: Editrice Morcelliana, 1963), p. 193. El autor se refiere además al antiguo valón treismes ('decimotercio' también). En continuidad con el neerlandés dertiendag.

18 Refranes que tomo, respectivamente, de estas dos obras: Xesús FERro Ruibal (director), Diccionario dos nomes galegos (Vigo: Ir Indo, 1992), p. 338; Antoni M. AlCOVER / Francesc de B. MOLL, Diccionari català-valencià-balear (Palma de Mallorca: Editorial Moll, 1980, 10 vols.), s.v. Llucia o Llúcia [con las siglas DCVB citaré este último diccionario en adelante].

19 La alusión a la Bisbal, seguramente ayudada por la rima con Nadal, se hace de mal interpretar. Pudiera tener que ver con la capilla anexa a la Catedral de Barcelona, situada frente al palacio episcopal. $O$ acaso con cierto santuario dedicado a Santa Lucía en la localidad de la Bisbal d'Empordà (DCVB, s.v. Llucia o Llícia [n. 18]).

20 REAl ACADEmia ESPAÑola, Diccionario de la lengua española (Madrid: EspasaCalpe, 1992, 21:" ed.), s.v. cabañuela [DRAE en adelante]. 
No sólo doce, sino también dieciocho o veinticuatro días. Cantidad, la última, que responde a docenas dobles. Bastante comunes, como se comprobará. En relación doblemente directa con los meses pronosticados, o bien directa (la primera docena) e inversa (la segunda). De un cálculo de 18 días, en cambio, sólo tengo constancia en las pintas costarricenses $(3.2, \mathrm{c})$, en que los 12 primeros días de enero vaticinan los doce meses del año, y los 6 siguientes ( 13 al 18), otra vez los meses, pero por parejas.

Enero y agosto alojan estas docenas (simples, medias o dobles) de días, según la definición académica.

Agosto acoge las cabañuelas que testimonian en el ámbito peninsular de habla castellana diversas fuentes (3.3; 4.2). De agosto y de la Península Ibérica son también un par de noticias, del catalán de Alicante y del vasco de Vizcaya (3.3). De agosto e insulares, las cabanelles menorquinas y el Compte de Salomó mallorquín (3.3), que cubren los tres primeros días del mes (no doce, sino tres; singular rareza). Rareza del mes de agosto en este renovarse de los años que es la previsión de los doce meses. Agosteña previsión, lejos del Año Nuevo vigente, y escasamente representada en el conjunto romance. Ya que lo más habitual en mis testimonios románicos europeos (y lo general en los americanos) es que los doce días (más doce ocasionalmente) de la previsión se sitúen entre diciembre y enero, antes o después de dos fechas cruciales, Navidad y Año Nuevo. En esta otra zona del calendario, los doce días presentan una interesante casuística de distribución, según los lugares. Baste leer ahora la siguiente (y densa) cita, a propósito de los significados que visten a los continuadores y derivados del latín CALENDAE (o CALENDAS).

I 12 giorni di festa', per lo più in Provenza, Italia settentrionale, nella zona di Pistoia (Toscana) e Calabria (ma non gli stessi ovunque: in Provenza i 12 giorni che precedono Natale, a Parma i 12 giorni che seguono Natale, nella zona di Mantova e Pistoia i primi 12 giorni di gennaio, nella zona di Genova gli ultimi 12 giorni di dicembre, in Calabria, nel Rovigno e nel Rouergue i dodici giorni tra S. Lucia (il 13 dicembre) e Natale). Da questi 12 giorni gli agricoltori di solito deducono previsioni meteorologiche per i primi mesi del Nuovo Anno (Merlo 1904 185, e n.1); AIS P.121: jours de la kalandra 'i giorni prima e dopo Natale' (significato incerto secondo l'informatore); AIS P.723 in Campania [e kkalennE] 'i giorni dal 13 al 24 dicembre', che sono usati come pronostico meteorologico per i mesi seguenti (AIS 781 legenda); nella regione di Pistoia, i primi 12 giorni dell'anno rappresentano i 12 mesi dell'anno $[. . .]^{21}$

21 Mario AlineI, "I nomi europei del 'Natale', Bollettino dell'Atlante Linguistico Italiano, 19 (1995), pp. 5-46 (y concretamente la p. 23). Como el autor en esta cita, también yo aprovecho datos de las dos obras siguientes: Clemente MERLO, I nomi 
En un contexto festivo, como el que proporciona el ciclo natalicio cristiano (incluido el advenimiento del Año Nuevo), no es infrecuente hallar alusiones a 'doce días de fiesta' sin más. Esa me parece la lectura esencial de la cita. Doce días de los que a menudo ("di solito" en palabras de Alinei) los agricultores deducen previsiones meteorológicas para los meses del año entrante. Doce días que preparan el camino a una fiesta principal (Navidad, Año Nuevo), o bien la prolongan. Doce días para doce meses. Enero a diciembre, cuando las correspondencias son directas. Diciembre a enero, cuando (a partir de las docenas de vuelta) las correspondencias son inversas.

Cuando la previsión docenaria se proyecta desde agosto, como en las cabañuelas castellanas, los meses pronosticados pueden seguir cronológicamente a ese mismo mes, de manera directa o inversa, o corresponder a los del año (aún lejano) por venir, también de manera directa o inversa.

Al margen de toda esta casuística, se suele tener por infalible la previsión cuando, en docenas dobles, hay coincidencia entre lo que apunta una fecha de la primera docena y su duplicada de la segunda. Pero también se dan, aquí y allá, casos de especialización de los pronósticos dobles, con correspondencias particularizadas, entre partes de cada jornada (mañana, tarde) y de cada mes (cuarto lunar, quincena). Ocasionalmente también, puede haber un día, anterior o posterior al cómputo docenario, cuya previsión tiene regencia general para todo el año. $\mathrm{Y}$ hasta prevalencia sobre lo que dicten las docenas correspondientes. Incluso cuatro días previos a la docena, para gobernar las cuatro estaciones del año.

Intentaré poner orden a todo este embrollo, y administrar informaciones más precisas, en lo que sigue ${ }^{22}$.

romanzi delle stagioni e dei mesi. Studiati particolarmente nei dialetti ladini, italiani, franco-provenzali e provenzali (Torino: Ermanno Loescher, 1904); Karl JABERG / Jakob JuD, Sprach- und Sachatlas Italiens und der Südschweiz [Atlante Italo-svizzero] (Zofingen, 1928-1940, 8 vols.) [citado en adelante como AIS]. Para otras consideraciones sobre los continuadores y derivados de CALENDAE (-AS), véase el punto 4.1.

22 Algunas precisiones.

1) En el catálogo de puntos de este apartado señalo de manera telegráfica los días de principio y término de cada docena, y a continuación (entre paréntesis) el primero y el último mes de la docena correspondiente (con la añadidura de una $I$, cursiva y mayúscula, en caso de correspondencia inversa). Si los días de inicio y fin del recuento no están expresados inequívocamente, traslado la indefinición al catálogo. Otro tanto hago, si me parece dudosa la correspondencia de meses. En caso de docenas dobles, marco una separación de doble barra inclinada $[/ /$ entre una y otra docena (con las respectivas correspondencias). Reservo el uso de la barra (inclinada) simple para indicar la coexistencia de variantes en la denominación de las docenas. 


\subsection{ANTES Y DESPUÉS DE NAVIDAD}

El natalicio de Cristo, que continúa en la fecha del 25 de diciembre la celebración precristiana del Dies Natalis Solis Invicti de los romanos ${ }^{23}$, constituye el eje en torno al cual se dispone la docena de días. Simple (antes o después del día de Navidad) o doble (antes y después del mismo). Excluido siempre en mi corpus el 25, cuando lo precede la docena (del 13 al 24). Asimismo en las témpores mallorquinas $(3.1, \mathrm{k})$, que se cuentan del 12 al 23 (toda una rareza). En general excluido de la docena de días que cuentan a partir del de Navidad, del 26 de diciembre al 6 de enero (Epifanía); si bien no es infrecuente su inclusión en el recuento, hasta la vigilia de Reyes, el 5 de enero. Media docena sólo (de días y de meses) computa mi testimonio brasileño de 3.1 (b), de acuerdo con el clima de la zona.

Detalles aparte, tal disposición de los cómputos, antes y después de Navidad, nos transmiten respectivamente un par de minitextos proverbiales, especie de refranes del calendario, en portugués y en francés.

2) Tras cada epígrafe, dispongo las denominaciones pertinentes, simples o dobles (a veces las hay simples que designan indistintamente docenas duplicadas), y las remito de manera sistemática al apartado 4 (en que se abordan diversos aspectos de índole léxica). Asimismo aporto las noticias sin nombre explícito. $\mathrm{Y}$ a todo ello añado la localización románica, y la fuente, oral o escrita.

3) Mantengo las transcripciones originales, con la salvedad de la letra inicial, que escribo sistemáticamente en minúscula (y que en las fuentes consultadas encuentro tanto en mayúscula como en minúscula, de manera algo aleatoria a veces). Sólo escapa a este criterio del uso de la inicial minúscula el testimonio en alemán del substantivo compuesto Lostage (3.1 (c)), en respeto a la ortografía de esta lengua. En algún caso me permito la licencia de convertir a grafía convencional alguna transcripción fonética de mis fuentes (así a partir del AIS [n. 21]), obviando algún pormenor formal sin transcendencia en lo léxico.

4) Ocasionalmente hago acompañar el artículo a estas denominaciones substantivas, cuando lo registra el original y me parece de interés. $\mathrm{Y}$ anoto entre paréntesis la indicación de género, masculino (m.) o femenino (f.), y de número, singular (s.) o plural (pl.), siempre que sean inequívocos tales datos gramaticales (proporcionados por la fuente de consulta, o garantizados por otros indicios de toda evidencia). Cuando el dato no es seguro, lo anoto con un interrogante. Como en el caso de algunos continuadores directos del lat. CALENDAE/-AS, aunque pudiera darse casi por cierto que continúan también el género femenino etimológico. O en el caso, algo más incierto, de los derivados por sufijación. A unos y a otros me refiero (respectivamente) en 4.1 (a) y (b).

23 Sobre los orígenes precristianos de la Navidad, véase ALINEI, "I nomi europei del 'Natale', pp. 5-8, 14 (n. 21). 


\author{
Assim como vires o tempo de Santa Luzia a Natal \\ assim estará o ano mês a mês até final ${ }^{24}$ \\ Regarde comme sont menées \\ Depuis Noël douze journées, \\ Car suivant ces douze jours, \\ Les douze mois auront leur cours ${ }^{25}$
}

\title{
3.1,a) 13 al 24 de diciembre (enero a diciembre)
}

- $i$ calenne (f.?,pl.): Cosenza, Calabria ${ }^{26}$; cf. 4.1 (a).

- e kkalenne (f.,pl.): Montefusco, Campania ${ }^{27}$; cf. 4.1 (a).

- li car(i)ènnuli (m/f.?,pl.): Modica, Sicilia ${ }^{28}$; cf. 4.1 (b).

- calendriéu/calandréu (m.,pl.): provenzal de la ribera del Ródano ${ }^{29}$; cf. 4.1 (b)

- li coumtié (m.,pl.): provenzal antiguo ${ }^{30}$; cf. 4.3 (c).

- jours compteurs (m.,pl.): Vaucluse, Provenza ${ }^{31}$. Parecen adaptación al francés de una forma dialectal más genuina, como la precedente, a no ser que se trate de francés regional. Cf. 4.3 (c).

- yúorne kuntáte (m.,pl.): Calabria ${ }^{32}$; cf. 4.3 (c).

Sin denominación explícita: Manacor, Mallorca ${ }^{33}$; y varios lugares de Cataluña, sin determinar ${ }^{34}$.

24 José Alves ReIs, Provérbios e ditos populares (Lisboa: Litexa Editora, 1996), p. 217.

25 Cellard / Dubois, Dictons, p. 184 (n. 4).

26 Jakob JuD, "Sur l'histoire de la terminologie ecclésiastique de la France et de l'Italie (avec 7 cartes)", Revue de Linguistique Romane, X (1934), pp. 1-62 (y concretamente la p. 14).

27 ALINEI, "I nomi europei del 'Natale', p. 23 (n. 21); quien lo toma del AIS (n. 21), mapa 781, localidad 723.

28 Giuseppe PITRE, Proverbi siciliani raccolti e confrontati con quelli degli altri dialetti d'Italia (Palermo: Luigi Pedone Lauriel, 1880, 4 vols.), III, p. 26.

29 Frederic Mistral, Lou Tresor dóu Felibrige ou Dictionnaire Provençal-Français (Aix-en-Provence, 1878-1886, 2 vols.), s.v. calendriéu, calandréu.

30 Mistral, Lou tresor, s.v. coumtié (n. 29).

31 Proverbes et dictons agricoles de France (Paris: Berger-Lebraut et $\mathrm{C}^{\mathrm{ie}} /$ LibrairesÉditeurs, 1872), p. 101.

32 AIS (n. 21), mapa 781 (localidad 750, cuyo nombre no aparece en el mapa 1 del atlas: Nomi ufficiali dei paesi esplorati).

33 DCVB, s.v. Llucia o Llúcia (n. 18).

34 Cels Gomis, Meteorología y agricultura populars ab gran nombre de confrontacions (Barcelona: Llibrería Dr. D. Álvar Verdaguer, 1888), pp. 101-102. 


\section{1,b) Seis dias, del 13 de diciembre - Santa Lucía-al 18 (enero a junio) \\ - experiências de Santa Luzia (f.,pl.): Ceará, Brasil ${ }^{35}$; cf. 4.3 (h).}

\section{1,c) Entre Noël et les Rois / 26 de diciembre al 6 de enero [?] (enero a diciembre)}

Les jours entre Noël et les Rois

indiquent le temps des douze mois ${ }^{36}$

Este dicton francés no especifica el principio ni el término de los doce días (¿Navidad excluida y Epifanía incluida? ¿viceversa?). Entre Navidad y Reyes se sitúan en cualquier caso los jours mâles (m.,pl.; cf. 4.3,h) o jours de sort (m.,pl.; cf. 4.3,f) que registran las dos obras citadas en la anterior nota 36. Jours de sort que la segunda atribuye con tal nombre a Bélgica. Y de Bélgica es también la noticia que sitúa vagamente la docena en los "12 jours d'après la N[oël], ${ }^{37}$, sin aportar denominación explícita.

Jours des lots, en los Vosgos, según cierta antigua información, que señala el de Reyes como último día del recuento ${ }^{38}$, y relaciona los doce días de la predicción con un curioso método adivinatorio de doce indicios materiales (v. 5).

Asimismo entre Navidad y Reyes se acredita en la Suiza de habla alemana el pronóstico para los doce meses ${ }^{39}$. Con la denominación de Lostage

35 Theophilo Braga, O povo portuguez nos seus costumes, crenças e tradições (Lisboa: Livraria Ferreira-Editora, 1885, 2 vols.), II, p. 32; Luís DA CÂmara CASCudo, Dicionário do folclore brasileiro (São Paulo: Editora da Universidade de São Paulo, 1988, 6." ed.), s.v. chuva. Ambas obras acreditan este vaticinio de sólo media docena de días, adecuado al clima de Ceará, con una época de lluvias de seis meses (de enero a junio). Lo que, por otra parte, sintoniza con el indicio material de las seis piedras de sal observadas en su comportamiento del 12 al 13 de diciembre (tal como describo en el apartado 5).

36 Cellard / Dubois, Dictons, p. 184 (n. 4); Florence Montreynaud / Agnès Pierron / François SuZzoni, Dictionnaire de proverbes et dictons. La sagesse du monde entier (Paris: Les usuels du Robert, 1994), p. 277.

37 J. Haust / L. REMACLE / É. Legros, Atlas linguistique de la Wallonie (Liège, 1953), vol. 3 (1955), p. 349 [citado en adelante como $A L W$ ].

38 Proverbes, pp. 118-119 (n. 31): “Au jour des Rois, qui est le dernier des jours des lots".

39 Bauernregeln. Eine schweizerische Sammlung mit Erläuterungen von Albert HAUSER (Zürich und München: Artemis Verlag, 1975, 2." ed.), p. 66 y passim. 
(m.,pl.; cf. 4.3,f) y variantes similares, o sin denominación explícita. Con explícita mención de los días de principio y término del recuento (del 26 de enero - San Esteban- a la Epifanía) o sin ella.

Lostage y jours des lots. 'Días de los lotes, o de las suertes', en versión germánica y romance.

\section{1,d) 25 de diciembre al 5 de enero (enero a diciembre)}

Noticia de $1617^{40}$ para el ámbito catalán. Sin denominación explícita.

3.1,e) 13 al 24 de diciembre (enero a diciembre) // 26 de diciembre al 6 de enero (diciembre a enero, $I$ )

- calandras (f.,pl.): Sariñena, Huesca ${ }^{41}$; en diversos puntos del Alto Aragón $^{42}$; cf. 4.1 (a).

- as calandras (f.,pl.) // - de retaculas: Biescas, Huesca ${ }^{43}$; cf. 4.1 (a) y 4.4 .

- as calandrias (f.,pl.): Guaso, Alto Aragón ${ }^{44}$; cf. 4.1 (a).

- calendas / recalendas (f.,pl.): Puebla de Arenoso (Castellón) y San Agustín (Teruel) ${ }^{45}$, localidades vecinas, de habla castellana ${ }^{46}$; cf. 4.1 (a) y (b), y 4.4 .

40 MiQuel Agustí, Llibre dels secrets d'agricultura, casa mística i pastoril [Estampat en Barcelona en la Estampa de Esteue Lliberós, Any M.DC.XVII]. Edició facsímil (Barcelona: Editorial Alta Fulla, 1988)], Llibre Primer, Cap. I/fol. 4.

${ }^{41}$ "As calandras, un viejo sistema para predecir el tiempo", Quio. Revista de Sariñena y Comarca, 55 (1997), p. 5.

${ }^{42}$ M." Pilar Barrabés / M." José Escario / M." José Madonar / Ma Pilar Moreno, "Las calandras y la predicción meteorológica en el Altoaragón [sich, Jornadas de Cultura Altoaragonesa (1983) (Huesca: Instituto de Estudios Altoaragoneses, 1986).

43 VV AA, Albada al Nacimiento. La Navidad en Aragón (Zaragoza: Caja de Ahorros Inmaculada, 1996), pp. 34-35.

44 Rafael ANDOLZ, Los aragoneses. Los ciclos del año, el invierno (Zaragoza: Mira Editores, 1998), Tomo II, p. 34, en la nota 15.

45 A propósito de las calendas y recalendas de esta localidad turolense, Anna Bertolin me transmite un simpático testimonio paremiológico, que alude a la época de la matanza.

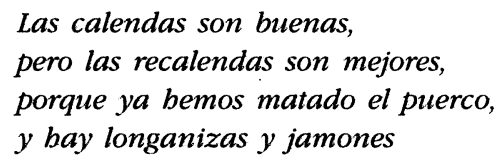

46 Información oral de familiares y paisanos, en ambos casos. 
- caliendes (f.,pl.): en la localidad catalanohablante de Atzeneta del Maestrat, Castellón ${ }^{47}$; cf. 4.1 (a).

- signos (m.,pl.): Huerta Oscense ${ }^{48}$; y en catalán (seguramente castellanismo) ${ }^{49}$; cf. 4.3 (d).

— signes del cel (signes dobles) (m.,pl.): en el ámbito catalán ${ }^{50}$; cf. 4.3 (d) y 4.4 .

- tretzenades (de devant // de recules) (f.,pl.): Rossell, Baix Maestrat ${ }^{51}$; tretzenaes (f.,pl.): Benassal, Alt Maestrat ${ }^{52}$; ambas, localidades catalanohablantes de la provincia de Castellón; cf. 4.3 (h) y 4.4.

- pornostico [sic] (m.s.), variante popular altoaragonesa de pronósti$\operatorname{co}^{53}$; cf. 4.3 (h).

- as canablas (f.,pl.): Escapa, Alto Aragón ${ }^{54}$; cf. 4.3 (h).

3.1,f) 13 al 24 de diciembre // 26 de diciembre al 6 de enero (sin indicación de correspondencias con meses)

- quendas (f.,pl.): en portugués ${ }^{55}$; cf. 4.1 (a).

- compte del Rei Salomó (m.,s.): Mallorca ${ }^{56}$; cf. 4.3 (c).

47 Noticia de Lola Monfort.

48 BARRABÉs et alii, "Las calandras" (n. 42).

49 Sebastià FARNÉs, Paremiologia catalana comparada. Edició a cura de Jaume VIDAL Alcover, Magí Sunyer i Josep Lluís Savall. Amb la col.laboració de Josep M. Pujol (Barcelona: Columna, 1992, 6 volúmenes publicados hasta 1997), V (1996), p. 565.

50 Joan AMADES, Costumari català (Navarra: Cercle de Lectors / Salvat, 1989, 16 vols.), XVI (1989), p. 121.

${ }^{51}$ José Enrique Gargallo GIL / Miquel Àngel Pradilla Cardona, El joc ancestral de la paraula. Llengua, cultura popular i refranyer a Rossell (Baix Maestrat) (Benicarló: Edicions Alambor, 1997), pp. 52-54.

52 Información de Pere-Enric Barreda Edo.

53 ANDOlZ, Los aragoneses, p. 34, en la nota 15 [de ANDOLZ] (n. 44 de mi texto).

54 Ibidem.

55 Braga, O povo portuguez, II, p. 322 (n. 35); António DE MORAIS Silva, Grande Dicionário da Lingua Portuguesa (Lisboa: Ed. Confluência, 1948, $10^{\mathrm{a}}$ ed., 12 vols.), s.v. quendas.

56 AmAdes, Costumari, I, p. 90 (n. 50). 
3.1,g) 13 al 24 de diciembre (primeras quincenas de enero a diciembre) // 26 de diciembre al 6 de enero (segundas quincenas de enero a diciembre)

- los doce dias (m.,pl.) o el calendario (m.,s.): Soria ${ }^{57}$; cf. 4.3 (b) y (a), respectivamente.

3.1,h) 13 al 24 de diciembre (enero a diciembre, mañanas) // 26 de diciembre al 6 de enero (enero a diciembre, tardes) [?]

- calendrines o calandres (f.,pl.): en el catalán de Terrats, Aspres de Rosselló $^{58}$; cf. 4.1 (b) y (a), respectivamente.

3.1,i) 13 al 24 de diciembre (enero a diciembre, mañanas) // 25 de diciembre al 5 de enero (enero a diciembre, tardes) [?]

- calandras (f.,pl.): Alto Aragón ${ }^{59}$; cf. 4.1 (a).

57 Ángel CARrIL RAMOS, "Etnometeorología en Castilla y León (acercamiento a los conocimientos populares a través de la previsión del tiempo, su mundo y contexto cultural, Revista de Dialectologia y Tradiciones Populares, XLIII (1988), pp. 119-131 (y concretamente la p. 127).

58 Joan COROMINES, Diccionari etimològic $i$ complementari de la llengua catalana (Barcelona: Curial Edicions Catalanes / Caixa de Pensions "La Caixa", 1980-1991, 9 vols.), s.v. calendari (noticia de 1960) [en adelante citaré DECat]. Por más que se me hace algo extraña esta previsión para las mañanas y las tardes de los meses respectivos, tal parece que se ha de interpretar a Coromines:

[...] se'n serveixen com a pronòstic per saber el temps que farà el matí en els 12 mesos vinents, i els 12 dies després de Nadal, per saber el temps que hi farà a les tardes.

A no ser que tomemos las mañanas como unidades de vaticinio en la primera docena de días, y las tardes para la segunda. Lo que se me antoja menos rebuscado, pero también menos acorde con el redactado de esta fuente.

59 Consideración semejante a la del caso anterior me merece esta otra noticia, que figura en cierto calendario para 1998 del Consello d'a Fabla Aragonesa. 
3.1,j) 13 al 24 de diciembre (enero a diciembre) // 25 de diciembre al 5 de enero (diciembre a enero, $I$ )

- as têmporas o arremessas (f.,pl.): en la región portuguesa del Miño ${ }^{60}$; têmporas, en el norte de Portugal; arremedas (f.,pl.) o arremedares (m.,pl.) en Guimarães (en el norte portugués, también); arremedar (de ida) // desarremedar (de vuelta) —ambos en singular- ${ }^{61}$; cf. 4.3 (e) y (h), 4.4.

- tretzenaes (f.,pl.) // - de recules: en la localidad catalanohablante de la Fresneda, Matarraña, Teruel ${ }^{62}$; cf. 4.3 (h) y 4.4.

\section{$3.1, \mathrm{k}) 12$ al 23 de diciembre [sic] (enero a diciembre) // 26 de diciembre al 6 de enero (de nuevo enero a diciembre)}

- témpores (f.,pl.) // — del moro: Mallorca ${ }^{63}$; cf. 4.3 (e) y 4.4.

\subsection{ANTES y DESPUÉS DE AÑo Nuevo}

Sólo un par de noticias abonan la docena inmediatamente previa al Año Nuevo (3.2,a). En cambio, los primeros 12 días de enero son secundados en diversos lugares romances, y en algunos del territorio de lengua vasca $(3.2, \mathrm{~b})$. Doce días redoblados con otros doce (en correspondencia directa o inversa de meses) en no pocos testimonios romances (de Hispanoamérica dos de ellos: 3.2,d). Doce + doce redondeados o desmentidos en su conjunto por el 25 (Conversión de San Pablo), día de vaticinio general para el año en las regiones italianas del Véneto y la EmiliaRomagna $(3.2, \mathrm{~g}$ y h). Predicción global para todo el año se concede por

60 P.[adr]e CunHa BRITO, "Etnografia minhota”, Revista Lusitana (Nova Série), XV (1992), pp. 290-311 (y concretamente las pp. 307-308).

${ }^{61}$ Todo ello, según datos de CÂMARA, Dicionário, s.v. chuva (n. 35). Aporta copiosas fuentes y citas, que no reproduzco.

62 Rafael FERRER BURGUÉs, Literatura oral de la Fresneda (Calaceit: Ajuntament de la Fresneda / Associació Cultural del Matarranya, 1992), pp. 22-23.

63 Antoni Galmés Riera, Cultura Popular Mallorquina. Aplec de Pautes (Palma de Mallorca: Caixa de Balears "Sa Nostra", 1982), p. 154. Muy meticulosa, por cierto, la distribución temporal que detalla el autor:

[...] les hores del dia, eren, més o manco, els dies del mes; el temps que feia cada dia i cada hora d'aquells dotze dies, era el temps — pluja, vent o ennigulat- que feria al llarg dels dotze mesos [...] 
su parte al 1 de enero en la zona de Areny de Noguera ${ }^{64}$, en el Aragón de lengua catalana rayano con Cataluña; primero de año al que sigue la doble docena $(2-13,14-25)$ en esas tierras de frontera. $Y$ hasta queda espacio entre las variantes de este punto para una media (doble) docena $(3.2, \mathrm{c}$ ).

\section{2,a) 20 al 31 de diciembre (enero a diciembre)}

- koende / kaende (f.?,pl.): Génova ${ }^{65}$; cf. 4.1 (a).

- Sin denominación explícita: Azores ${ }^{66}$.

\section{2,b) 1 al 12 de enero (enero a diciembre)}

Les douze premiers jours de l'année indiquent le temps qu'il fera les douze mois de l'année ${ }^{67}$. Dicton que sintoniza con diversas noticias sobre un tal vaticinio (sin denominación explícita) en distintas partes del dominio lingüístico francés (de Europa). A saber: en las demarcaciones de Basses Pyrénées, Somme (Picardía) y Finisterre (Bretaña) ${ }^{68}$; en Bélgica ${ }^{69}$.

Otras noticias (sin nombre) de lo mismo las he hallado para el ámbito catalán ${ }^{70} \mathrm{y}$ para el portugués ${ }^{71}$. Sí ofrecen denominación, en cambio, los siguientes testimonios.

- calende (f.,pl.): Toscana ${ }^{72}$; cf. 4.1 (a).

- calendario (m.,s.): Romagna ${ }^{73}$; cf. 4.3 (a).

- cabañuelas (f.,pl.): del castellano, atestiguadas en el siglo XVIII por el Diccionario de Autoridades ${ }^{74}$; cf. 4.2 .

64 Areny de Noguera, en la versión catalana del topónimo, o Arén, en la castellana (o castellanizada), la que prefieren los autores del estudio que cito en 3.2 (i).

65 MERLO, I nomi romanzi, p. 185 (n. 21).

66 Braga, o povo portuguez, II, p. 332 (n. 35).

67 Cellard / Dubois, Dictons, p. 12 (n. 4).

68 Proverbes, p. 6 (n. 31).

69 $A L W, 3$ (1955), p. 349 (n. 37).

70 Gomis, Meteorología, p. 102 (n. 34).

71 BraGa, O povo portuguez, II, p. 253 (n. 35).

72 Dizionario enciclopedico italiano (Roma: Istituto della Enciclopedia Italiana / Istituto Poligrafico dello Stato, 1955-1961), s.v. calènde [sic].

73 Enciclopedia italiana di scienze, lettere ed arti (Roma: Istituto della Enciclopedia Italiana, 1949), s.v. calendario.

74 Real ACademia Española, Diccionario de Autoridades (Madrid: Gredos, 1984, 3 vols.) [Edición Facsímil del original de 1726-1739], s.v. cabañuela. 
- sortes (f.,pl.): en gallego ${ }^{75}$; con otra docena redoblada de resortes en el testimonio de 3.2 (f), en este mismo apartado. Para las denominaciones, cf. 4.3 (f) y 4.4.

- zotal-egunak ('días augurales') (pl.): en el vasco de Navarra, Lapurdi y Zuberoa ${ }^{76}$; cf. 4.3 (h).

- Sin denominación explícita: en el retorrománico de Suiza ${ }^{77}$.

\section{2,c) 1 al 12 de enero (enero a diciembre) // 13 al 18 de enero (enero a diciembre, de dos en dos meses)}

- pintas (f.,pl.): Costa Rica ${ }^{78}$; cf. 4.3 (h).

\section{2,d) 1 al 12 de enero (enero a diciembre) // 13 al 24 de enero (diciembre a enero, I)}

- cabañuelas (f.,pl.): México ${ }^{79}$; cf. 4.2 .

- cabañuelas (f.,pl.); cabañuelas grandes // - chiquitas: República Dominicana ${ }^{80}$; cf. 4.2 y 4.4 .

- al spèi dl an ('los espías del año') (m.?,pl.): Castel Bolognese, EmiliaRomagna ${ }^{81}$; cf. 4.3 (h).

- Noticia sin nombre, para el catalán ${ }^{82}$.

75 Real ACAdemia Galega, Diccionario da Real Academia Galega (A Coruña: Xerais, 1997), s.v. sorte.

76 Resurrección María DE AzKUE, Euskaleriaren Yakintza. Literatura popular del País Vasco (Madrid: Espasa Calpe), I (1935), p. 69; III (1945), p. 165.

77 HAUSER, Bauernregeln, p. 203 (n. 39).

78 Información oral, de diversos colegas costarricenses. La previsibilidad de la época de lluvias en Centroamérica no es impedimento para que se dé crédito a este método de predicción. Es más, mis informantes tenían por cierta la correspondencia entre meses (consabidamente) lluviosos y los respectivos días de enero, aun si para ello tales días estuviesen predestinados a ser también lluviosos. Por esa especie de predicción a la inversa, ya que se sabe con certeza que meses como septiembre y octubre vendrán con lluvia, otro tanto se esperará de cada 9,10 y 17 de enero previos.

79 Información oral.

80 Información oral.

81 Carlo LAPUCCI, Cielo a pecorelle. I segni del tempo nella meteorologia popolare (Milano: Garzanti, 1995, 3.: ed.), p. 145.

82 AMAdES, Costumari, II (1989), p. 14 (n. 50). 
3.2,e) 1 al 12 de enero (enero a diciembre) // 13 al 24 de enero (enero a diciembre, de nuevo)

- polas // repolas (f.pl.): San Andrés de Comesaña, parroquia de Vigo, Galicia ${ }^{83}$; cf. 4.3 (h) y 4.4 .

3.2,f) 1 al 12 de enero (enero a diciembre) // 13 al 24 de enero (sin indicación de correspondencias con meses)

- sortes // resortes (f.,pl.): Foz, Lugo ${ }^{84}$; cf. 4.3 (f) y 4.4.

- calendre // scalendre (f.?,pl.): Mantua, Lombardía ${ }^{85}$; cf. 4.1 (a) y (b), 4.4 .

\section{$3.2, \mathrm{~g}) 1$ al 12 de enero (enero a diciembre) // 13 al 24 de enero (diciembre} a enero, $I)+$ el 25 de enero (predicción anual)

La meteorología popular, expresada en refranes del calendario, concede al día 25 de enero (Conversión de San Pablo) un papel rector para todo el año en diversas áreas romances.

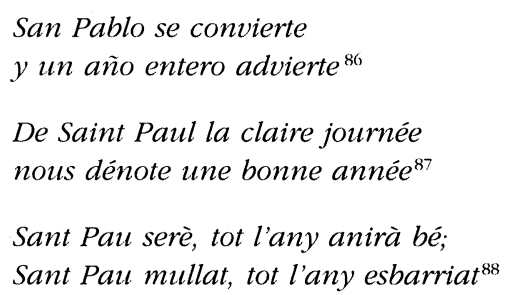

En el área véneta, San Paolo dei segni (como se le llama popularmente) ${ }^{89}$ ostenta el privilegio de confirmar o desmentir las predicciones (dobles) de las dos docenas de días previos.

83 Información oral de Helena González Fernández.

84 Manuel Alvar, Léxico de los marineros peninsulares (Madrid: Arco/Libros), I (1985), p. 448.

85 MERLO, I nomi romanzi, p. 185 (n. 21).

86 Luis MarTínez Kleiser, Refranero general ideológico español (Madrid: Real Academia Española, 1953) [Ed. facsímil, Madrid: Editorial Hernando, 1989], p. 197.

87 Cellard / Dubois, Dictons, p. 20 (n. 4).

$8 s$ Amades, Costumari, II (1989), p. 322 (n. 50).

89 Carlo LAPUCCI, 30 di conta novembre... I proverbi dei mesi (Milano: Garzanti, 1993), p. 50 
- endegaro (m.,s.) / endegari (m.,pl.) o calèndre (f.,pl.): Verona ${ }^{90}$; zorni endegari (m.,pl.): Véneto ${ }^{91}$; cf. 4.1 (a) y 4.3 (h).

\author{
No me curo de l'endegaro \\ se'l dì de San Paolo no xè né scuro, né ciaro ${ }^{92}$ \\ De le calèndre no me ne curo \\ purchè San Paolo no fassa scuro ${ }^{93}$
}

3.2,h) 1 al 12 de enero (enero a diciembre) // 13 al 24 de enero (sin indicación de correspondencias con meses) + el 25 de enero (predicción anual)

- càlenni // calindèn (f.?, pl.): Parma ${ }^{94}$; cf. 4.1 (a) y (b), 4.4. También aquí el 25 (San Pablo) confirma o desmiente los vaticinios previos.

S'la nota d'San Pävel l'è scura,

dil calen'ni [sic] ansòn s'in cura (Parma) ${ }^{95}$

3.2,i) 1 de enero (predicción anual) +2 al 13 de enero (enero a diciembre) // 14 al 25 de enero (diciembre a enero, I)

- calandras (f.,pl.): Areny de Noguera ${ }^{96}$; cf. 4.1 (a).

\title{
3.3. EN AGOSTO
}

$$
\begin{aligned}
& \text { Agosto está en el secreto } \\
& \text { de doce meses completos }
\end{aligned}
$$

90 Giuseppe RAma, Proverbi de Verona, "Pillole di saggezza popolare" (Bussolengo: Edizioni della Libreria di Demetra, 1994), pp. 99-100.

91 LAPUCCI, 30 di, p. 51 (n. 89).

92 Ibidem.

93 RAMA, Proverbi, p. 98 (n. 90).

9 Carlo RognONI, Raccolta di proverbi agrari e meteorologici del parmigiano (Parma: Edizioni Prograf, 1993), p. 35.

95 Ibidem.

96 BARrABÉs et alii, "Las calandras", p. 212 (n. 42).

97 Luis MARTÍNEZ KLEISER, El tiempo y los espacios de tiempo en los refranes (Madrid: Librería General de Victoriano Suárez, 1945), p. 280. 
Como instruye el refrán castellano, agosto guarda la suerte de doce meses por venir. Pero en este caso también los doce días del vaticinio y los doce meses vaticinados ofrecen una casuística de disposición y correspondencias al menos tan abundante como la de los dos apartados anteriores.

Docenas simples o dobles. Segundas docenas de predicción directa o inversa. Disposición de meses desde agosto (incluido) hasta julio del año siguiente (o a la inversa). Desde enero del año siguiente hasta diciembre (o a la inversa), en lo que se me figura una predicción excesivamente lejana, pues en el caso extremo de la correspondencia con diciembre habrán de transcurrir nada menos que quince meses hasta que se verifique la previsión.

Previsión con valor anual del primero de agosto, o exclusión de éste en el vaticinio $(3.3, c)$. Especial repartición de los cuatro primeros días del mes, prefiguradores de cuatro estaciones $(3.3, \mathrm{~d}$ y e). Partición de las jornadas $(3.3, a)$, hasta el mediodía (para las primeras quincenas de cada mes) y por la tarde (para las segundas). Y consideración aparte merecen los testimonios baleares de sólo tres días (los primeros de agosto), que guardan también la suerte de un año entero.

Todo ello en pleno estío, en contraste con el aire invernal que respiran los doce días en torno a la Navidad y el Año Nuevo. Docenas de tiempo de agosto. Pervivencia compartida, a mi juicio, de aquel mito del eterno retorno con que se inicia este texto, de los doce días en el renovarse de los años. Lejos aún del Año Nuevo, los $12(+12)$ días de agosto exhiben un carácter diferencial en el conjunto romance. $\mathrm{Y}$ en el conjunto del año su encuadre requiere una justificación.

Justificación que no pretendo irrefutable, pero que creo poder relacionar con lo que argumenta, a propósito de las cabanelles de Menorca, el autor de la cita siguiente.

A Menorca els tres primers dies d'agost, ço és la vigília, el dia i l'endemà de la Mare de Déu dels Àngels, són coneguts per "Cabanelles". El temps que fa aquests dies és, segons creença, indici del que farà la resta de l'any [...]

Evidentment, aquesta pràctica menorquina és una supervivència de la pràctica jueua de la libació de l'aigua; és cert que una mica esfumada.

L'única dificultat que hi ha per acoblar les "cabanelles" catalanes de l'Edat Mitja [la fiesta judía] i les "cabanelles" actuals de Menorca és l'escaure's les primeres pel setembre i les segones per l'agost. Això es resol facilment si es té en compte que les "Cabanelles" són una festa d'acció de gràcies per la collita i aquesta ja està recollida, a Menorca, a darreries de juliol i començament d'agost ${ }^{98}$.

98 Antoni Griera, "Les cabanelles", Homenatge a Antoni Rubió i Lluch. Miscel.lània d'estudis literaris, bistòrics i lingüistics (Barcelona, 1936), pp. 161-163 (y concretamente las pp. 162-163). 
En esta línea argumental, las caban(y)elles catalanas, como las cabañuelas castellanas (denominaciones para las que remito a 4.2), constituirían una suerte de derivación o especialización de la tradicional fiesta judía de los Tabernáculos. Fiesta en la que, según Mircea Eliade", "es cuando se decide la cantidad de lluvia concedida al año próximon. Celebrada en el mes de Tishri del calendario hebreo, allá por el equinoccio de otoño, duraba (y dura) en torno a una semana, del 15 de Tishri en adelante. Una semana que deslindaría el año, puesta la vista en los meses futuros ${ }^{100}$, acopiada la cosecha de los meses previos ${ }^{101}$.

La Fiesta de los Tabernáculos oscila de hecho entre los meses de septiembre y octubre de nuestro calendario de base romana, pero es evidente que supone un tránsito anual, una renovación del año (como nos ilustra Mircea Eliade en la cita siguiente).

[...] el Año Nuevo, la fiesta llamada de los Tabernáculos (bag hasukkot), fiesta de Yahvé por excelencia, se celebra el decimoquinto día del séptimo mes [...] antes de la adopción del calendario babilónico, el séptimo mes era el primero del calendario israelita ${ }^{102}$.

Es el mes que se inicia con el Año Nuevo propiamente dicho, la celebración de Rosh ha-shanab (literalmente, 'principio del año'). A saber, los dos primeros días del mes de Tishri, cuando apunta a verse la primera luna del año ${ }^{103}$.

Pensemos ahora en el antiguo séptimo mes de los romanos (SEPTEMBER), nuestro septiembre, que en sardo recibe el nombre de cabudanni/

99 EliADE, El mito, pp. 60-61 (n. 2).

100 En Israel, los meses de la época de lluvias, de octubre a mayo. Véase al respecto la Encyclopaedia Judaica (Jerusalem: Keter Publishing House, 1972), s.v. rain:

[...] rains fall in Israel only during the period October through May, which is called "the rainfall season" [...]

101 "La pasqua de las cabañas farás a ti siete días, quando ayuntares tu trigo e tu mosto [...]", leo en cierta versión (medieval y romanceada) de la Biblia: P. José LlAMAS (ed.), Biblias medievales romanceadas. Biblia medieval romanceada judio-cristiana. Versión del Antiguo Testamento en el siglo XIV, sobre los textos bebreo y latino (Madrid: CSIC, 1950) vol. I (Génesis-Reyes), p. 273 (Deuteronomio, cap. XVI). Una de tantas referencias bíblicas a la Fiesta judía. Denominada aquí pascua de las cabañas. Cabañas o cabañuelas, tabernáculos o enramadas sobre cuya motivación vuelvo en el punto 4.2 .

102 Eliade, El mito, p. 62 (n. 2).

103 Para otros detalles sobre el calendario judío y las fiestas de Año Nuevo y los Tabernáculos, remito a la Encyclopaedia Judaica (s.v. Rosh ba-shanab y Sukkot, respectivamente) [n. 100]. 
cabidanni (del lat. CAPUT ANNI). "Cabo o cabeza de año" que podría explicarse por ser éste el período de inicio del año agrícola en Cerdeña, pero que no excluye la interpretación alternativa (o complementaria) de una influencia hebrea, de un calco sobre la denominación judía de Rosh ha-shanah, la fiesta de entrada al año ${ }^{104}$.

Consideremos por fin la identidad denominativa entre las dos significaciones que alberga un mismo tipo léxico, cabañuelas/caban(y)elles. Con éste se nombran tanto la tradicional fiesta judía de los Tabernáculos como algunas variantes de la práctica de predicción anual que toman agosto como referencia. Así, las cabañuelas castellanas de este punto, o las peculiares cabanelles de Menorca (como se deja ver en la cita de Griera (v. nota 98).

Todo ello sopesado, la anticipación de en torno a un mes, desde la entrada equinoccial del otoño (la fiesta judía) hasta el mes de agosto (la predicción meteorológica), tal como se sugiere en aquella cita, me parece un argumento aceptable, al menos a falta de otro mejor. Quedan, por desventura, no pocos cabos por atar.

Lo que más me desconcierta de este tipo de pronósticos (desde agosto) es su distribución territorial con respecto a los vaticinios desde diciembre y/o enero. Tengo noticia de distintos testimonios de agosto en la Península (básicamente centro, norte, sur y sureste) y en las islas de Mallorca y Menorca. Pero en conjunto no se prestan cómodamente a la interpretación (simplista) del "substrato".

Así, la forma vasca (vizcaína) bilegunak $(3.3, \mathrm{~g})$ es de agosto, al igual que las cabañuelas castellanas, y a diferencia de aquella otra vasca, de enero (zotal-egunak), con localizaciones más orientales (3.2,b). Y la misma isla (Mallorca) y casi el mismo nombre comparten mis testimonios sobre un compte del Rei Salomó (en torno a la Navidad, 3.1,f) y un compte de Salomó (de agosto, 3.3,h).

Por otra parte, la interpretación del "substrato judío" requeriría siquiera algún rastro de caban(y)elles de agosto, por ejemplo, en lugares como Barcelona o Gerona, que en otro tiempo albergaron importantes juderías. $\mathrm{Y}$ el caso es que no tengo noticia de tal predicción en el nordeste peninsular. Tampoco en Aragón. Además resulta difícil de determinar por qué en unos casos las predicciones de agosto rigen un año desde ese mismo mes, y en otros, a más distancia, gobiernan el año siguiente. La primera opción responde esencialmente a la misma estrategia (crono)lógica que da sentido a las predicciones desde diciembre y enero $(3.1,3.2)$, y bien pudiera ser la primitiva. La otra, más forzada, quizá desplazó secundaria-

104 Véase al respecto Tagliavini, Storia, pp. 160-161 (n. 17). 
mente la previsión anual para adecuarse al curso de los meses (de enero a diciembre) según el calendario vigente, de base romana.

Otra explicación requieren las cabañuelas americanas, que vaticinan desde enero el año entrante $(3.2, d)$. Cabañuelas de base hispánica, que se trasladaron tal vez de agosto a enero, también secundariamente.

\section{3,a) 1 al 12 (agosto a julio) // 13 al 24 (julio a agosto, I)}

- cabañuelas (f.,pl.) (de ida // de retorno): Murcia ${ }^{105}$.

- cabañuelas // los (dias) retorneros: Osuna, Sevilla ${ }^{106}$.

- cabañuelas // (-) retorneras: Osuna, Sevilla ${ }^{107}$.

Remito, por lo demás, para otros aspectos léxicos de estas tres informaciones, a 4.2 y 4.4 .

- cabanyoles/cabanyueles [¿adaptación del castellano?] (f.,pl.); anaes // retornaes (f.,pl.): Alicante, en zona de habla catalana ${ }^{108}$; cf. 4.2 y 4.4 .

De la provincia de Salamanca ${ }^{109}$, estas otras cabañuelas (f.,pl.), de las que entresaco algunas correspondencias: 3.2 (b) a (e) ${ }^{110}$. En algunos lugares se dan las denominaciones alternativas de caniculas o cabichuelas.

105 Gran enciclopedia de la región de Murcia (Murcia: Ayalga Ediciones, 1992), s.v. cabañuelas; MARTÍNEz KLEISER, El tiempo, pp. 277-278 (n. 97).

106 MARTÍNEz KLEISER, ibidem; información procedente, en último extremo, de la obra paremiológica de Francisco Rodríguez Marín. Reproduce además aquel autor (MARTínez KleISER, El tiempo, p. 277) cierta fuente murciana en que se precisa: "Cada mañana y cada tarde denotará, por su temperatura, la que haya de hacer en los cuartos lunares correspondientes, pues dos días abarcan el pronóstico de un mes completo $[\ldots]_{\text {. }}$.

107 Francisco Rodríguez MARín, Los refranes del almanaque. Recogidos, explicados $y$ concordados con los de varios países románicos (Sevilla: Imp. de Francisco de $\mathrm{P}$. Díaz., 1896), p. 164.

108 Alfredo RAMÓN MORTE, Clima y tradición oral en la provincia de Alicante (Alicante: Instituto de Cultura "Juan Gil-Albert" / Diputación de Alicante, 1992), pp. 199200.

109 Juan Francisco Blanco, El tiempo. Meteorologia y cronología populares (Salamanca: Ediciones de la Diputación de Salamanca / Archivo de Tradiciones Salmantinas, 1987), pp. 59-61.

110 Remito, de paso, al trabajo sobre etnometeorología en Castilla y León de CARRIL RAMOS ("Etnometeorología”, pp. 127-128) [n. 57], cuyos datos para Salamanca coinciden esencialmente con los de Blanco, El tiempo (n. 109). A propósito de la distribución de las jornadas y de los meses, señala este otro autor: 
3.3,b) 1 al 12 (enero a diciembre)

3.3,c) 1 (no rige / es de juicio general para el año) +2 al 13 (enero a diciembre)

- cabichuelas (f.,pl.), con un primer día "del Juicio Final" [?] ${ }^{111}$; cf. $4.3(\mathrm{~h})$.

3.3,d) 1 al 4 (las 4 estaciones) +5 al 16 (enero a diciembre)

3.3,e) 1 al 4 (las 4 estaciones) +5 al 16 (enero a diciembre) // 17 al 28 (diciembre a enero, I)

$3.3, \mathrm{f}) 14$ al 25 (enero a diciembre): llamadas en este caso canículas (f.,pl.) ${ }^{112}$; cf. 4.3 (h)

3.3,g) 1 al 12 (enero a diciembre) // 13 al 24 (enero a diciembre, de nuevo)

- bilegunak ('días de meses' literalmente) (pl.): en el vasco de Vizcaya $^{113}$; cf. $4.3(\mathrm{~h})$.

\section{3,h) 1, 2 y 3 (predicción de tres temporadas del año)}

- cabanelles (f.,pl.): Menorca ${ }^{114}$; predicción de tres temporadas, sin determinar; cf. 4.2 .

- compte de Salomó (m.,s.): Mallorca ${ }^{115}$; cf. 4.3 (c).

Los buenos "echadores" de cabañuelas pueden llegar a precisar, incluso, el tiempo por quincenas. La observación de las señales pertinentes antes del mediodía servirá para establecer la predicción de la primera quincena del mes correspondiente, y las de la tarde para la segunda. (BlanCO, El tiempo, p. 12 [n.109])

11 Así lo atestigua Blanco, El tiempo, p. 61 (n. 109). "Día del juicion, según el testimonio (también salmantino) de CARRIL RAMOS, "Etnometeorología", p. 127 (n. 57).

112 BlanCO, El tiempo, p. 61 (n. 109).

113 AZKUE, Literatura popular, I (1935), p. 69 (n. 76).

114 GrierA, "Les cabanelles", p. 162 (n. 98).

115 GalmÉs, Cultura Popular, p. 154 (n. 63); según este autor, «[...] el primer dia, temps a fer de Sant Miquel a Nadal; el segon, el de la hivernada; i el tercer, la primavera [...]. 


\section{LOS NOMBRES}

Agrupo en tres subapartados las denominaciones de estos días de predicción. En primer lugar (4.1), los herederos romances del lat. CALENDAE (-AS), que tienen representación en los espacios iberorrománico, galorrománico e italorrománico, las tres grandes parcelas de la Romania europea de donde procede mi cosecha léxica. Con distinción entre los continuadores directos de aquel étimo latino (a) y los derivados (b). En segundo lugar (4.2), las cabañuelas, de amplia difusión hispánica, y sus homólogas catalanas, las caban(y)elles. Ocupan el tercer apartado (4.3) las denominaciones restantes, especie de cajón de sastre en el que procuro poner algo de orden. Añado por fin un escueto apéndice (4.4), donde reúno por afinidades las denominaciones específicas para las docenas dobles.

Casi la totalidad del material léxico que aquí trato ha sido mencionado ya a propósito de las correspondencias entre días y meses (apartado 3). De modo que remito en cada caso al punto pertinente, donde se hallarán informaciones (también las bibliográficas y las de índole gramatical) que ya no reitero. Dobles remisiones requerirán no pocas denominaciones para las docenas dobles, en el apéndice final.

Hay, sin embargo, algunos datos léxicos nuevos. Docenas de días de las que no me consta su correspondencia precisa o su valor de predicción, y por eso no se han incluido en el apartado 3. Amén de informaciones varias que juzgo de interés.

\subsection{HEREDEROS ROMANCES DE CALENDAE (-AS)}

El plural femenino CALENDAE (en caso nominativo) o CALENDAS (en acusativo) 'primer día del mes' ha legado una considerable herencia léxica, rica de significados, tanto en el estricto mundo romance como en otras familias lingüísticas de Europa ${ }^{116}$. Su ligazón etimológica a 'lo primero' le habrá facilitado sin duda el camino hacia la idea general de inauguración y renovación de un período anual (el Año Nuevo) que transmiten nuestros 'doce días'. Y por otras vías semánticas parece que alcanzó a significar 'el día de Navidad', los doce precedentes (desde Santa Lucía) o los doce siguientes (hasta la Epifanía). En el sudeste de Francia, por ejemplo,

116 Véase al respecto: Merlo, I nomi romanzi, pp. 182-186 (n. 21); JUD, "Terminologie ecclésiastique", pp. 14-17 (n. 26); TAGliavini, Storia, pp. 183-184 (n. 17); AlineI, "I nomi europei del 'Natale'", pp. 22-26 (n. 21). 
CALENDAS habría designado al principio ${ }^{117}$ el ciclo de 12 días previos a la Navidad, y después la propia fiesta que cierra el ciclo. Algo así como en la cincuentena de días de Pentecostés, extendida nominalmente a la festividad que culmina este otro ciclo (móvil).

No siempre hay constancia, en la bibliografía consultada, del carácter meteorológico-augural de esos doce días, como ya se ha dicho (v. 3). Pero, sean o no días de predicción, queda fuera de duda su identidad esencial con los que prefiguran un nuevo año. Por ello los reúno indiscriminadamente en este apartado.

La idea básica de cómputo docenario los hermana a todos. Idea que ha alcanzado también a un singular método de cálculo para contar los días, un aparato hecho de cuerdas y antiguamente utilizado por los pastores pirenaicos de la Junquera: la calenda ${ }^{118}$. Rara forma en singular, que contrasta con las continuaciones (directas o derivadas) de las CALENDAS. Todas de número plural (como su étimo). Todas seguramente femeninas (como en latín), aunque no siempre mis fuentes expliciten el género.

\section{1,a) Continuadores directos}

Su forma presenta alguna anomalía con respecto a los dictados de la fonética histórica regular. Especialmente la inserción de una - $r$ - (como en las calandras altoaragonesas), que no resulta fácil de explicar (¿atracción analógica de otras voces con semejante terminación?). Algo que se extiende también a los derivados.

- calendos (Rouergue, Occitania) ${ }^{119}$; también occitanos son los testimonios de calendas ${ }^{120}$ y colendos [sic] ${ }^{121}$.

- calendas (Puebla de Arenoso, Castellón; San Agustín, Teruel; cf. 3.1,e); completadas con las recalendas (cf. 4.1,b).

- caliendes (Atzeneta del Maestrat; cf. 3.1,e); con un diptongo algo sorprendente, pues no se ajusta a la fonética histórica del catalán.

117 Según Jud, "Terminologie ecclésiastique", p. 14 (n. 26).

118 Joan AmADES, "Calendarios de analfabetos", Revista de Dialectología y Tradiciones Populares, IX (1953), pp. 416-466 (y concretamente las pp. 420-421).

119 Así en Merlo ( $I$ nomi romanzi, p. 185 [n. 21]), que acaso lo toma de Mistral (Lou tresor, s.v. calèndo y vars. [n. 29]).

120 Con esta otra grafía aparece en Louis ALIBERT, Dictionnaire occitan-français d'après les parlers languedociens (Toulouse: Institut d'Etudes Occitanes, 1966), s.v. calenda.

121 Jud, "Terminologie ecclésiastique», p. 14 (n. 26); quien anota asimismo la localización de Rouergue, y añade: "sounà colendos, c'est "Sonner les cloches tous les soirs pendant les jours qui précèdent la fête de Noël" [...]n. 
- quendas (en portugués); cf. 3.1,f).

- calende (Toscana); cf. 3.2,b).

- $i$ calenne (Cosenza, Calabria); cf. 3.1,a).

- e kkalenne (Montefusco, Campania); cf. 3.1,a).

- koende / kaende (Génova); cf. 3.2,a).

- càlenni (Parma; cf. 3.2,h); véase además calindèn (4.1,b), para la docena de complemento.

- caländ: Módena ${ }^{122}$.

- calendre (Mantua; cf. 3.2,f); véase también scalendre (4.1,b), para la correspondiente docena duplicada.

- calèndre (Verona; cf. 3.2,g); denominación con que se conoce asimismo el curioso vaticinio anual de los doce cascos de cebolla, o de las doce cáscaras de nuez, y los correspondientes pizcos de sal (para lo que remito al apartado 5).

- calandras (Alto Aragón); cf. 3.1 (e), 3.1 (i) y 3.2 (i); fer as calandras $^{123}$; para las calandras de retaculas véase 4.4 .

- as calandrias (Guaso, Alto Aragón); cf. 3.1 (e).

- calandres (en el catalán de Terrats, Aspres de Rosselló; cf. 3.1,h); también llamadas calendrines (4.1,b).

- kalenbre (Rovigno), '13 al 24 de diciembre'; no consta su valor de predicción ${ }^{124}$.

\section{1,b) Derivados}

Con prefijo:

- recalendas (Puebla de Arenoso, Castellón; San Agustín, Teruel; cf. 3.1,e); docena de complemento a las calendas (cf. 4.1,a).

- DIS-/DE-/EX- ${ }^{125}$ : descaländ (Módena) ${ }^{126}$ : scalendre (Mantua; cf. 3.2,f). Docenas de vuelta (cf. 4.1,a).

122 MeRLo, I nomi romanzi, p. 185 (n. 21). No consta valor de predicción, ni correspondencias, pero la anotación (escueta) de la forma adjunta descaländ es probable que aluda a una docena doble (cf. 4.4). Compárese con el caso siguiente.

123 Expresión que registra en Biescas Albada, p. 34 (n. 43).

124 MERLo, I nomi romanzi, p. 185 (n. 21); JUD, "Terminologie ecclésiastique", p. 14 (n. 26). Este último autor (p. 14, en la nota 3) remite a cierta referencia bibliográfica (Ive, Dialetti ladino-veneti dell' Istria, p. 32 ) en que se sugiere un cruce $(<$ calendae + décembre) para explicar tal variante de Rovigno.

${ }_{125}$ Que pudiera tener aquí un valor semejante al que expresa des- en el castellano deshacer, o desandar. Véase al respecto Gerhard RoHLFs, Grammatica storica della lingua italiana e dei suoi dialetti (Torino: Einaudi, 1966-1969, 3 vols.), III (1969), pp. 350-353. Compárese, además, con la forma portuguesa desarremedar $(3.1, \mathrm{j})$.

126 MERLo, I nomi romanzi, p. 185 (n. 21). 
Con sufijos diversos:

-ILE: calendriéu/calandréu (en provenzal); cf. 3.1,a).

-'ULE: li car(i)ènnuli (Sicilia; cf. 3.1,a); calènnule, '13 al 24 de diciembre' (Calabria) ${ }^{127}$.

-INAS: calendrines (en el catalán de Terrats, Aspres de Rosselló; cf. $3.1, \mathrm{~h})$, también llamadas calandres $(4.1, \mathrm{a})$; calindèn (Parma; docena de complemento; cf. 3.2,h).

\subsection{CABAÑuelas / CABAN(Y)ELles}

Cabañuelas figura como referente en el cuestionario utilizado para la elaboración del Léxico de los marineros peninsulares ${ }^{128}$. Las cabañuelas, llama genéricamente Manuel Toharia a este "antiquísimo método para la predicción del tiempon ${ }^{129}$.

Conozco en España cuatro tipos de "escuelas" cabañuelísticas, y seguramente existirán más. En Francia sé de dos escuelas de cabañuelas; y también serán más, a buen seguro. $\mathrm{Y}$ he leído que en Italia y en Inglaterra igualmente existe este tipo de predicciones ${ }^{130}$.

Se trata de usos de cabañuelas hechos desde la reflexión. Desde el ejercicio dialectológico o divulgativo, pensado y expresado en español. Es evidente, pues, que el término, descontextualizado de su empleo espontáneo y popular, se ha llevado también al terreno de la ciencia. A falta, seguramente, de una alternativa mejor. $\mathrm{Y}$ así vale para nombrar cualquier variante de este tipo de predicción, sea en área de habla castellana, sea en cualquier otra (romance o no).

Pero, en el estricto uso popular, cabañuelas, con esta hechura tan del romance castellano (-uelas < -ǑLAS), se circunscribe a tierras que hablan esa lengua, en España (3.3) o en América (3.2,d).

La identidad denominativa entre el método de predicción y la antigua fiesta judía (también llamada de los Tabernáculos) ${ }^{131}$ se expresa claramente en el Diccionario de Autoridades. También la motivación original de este derivado diminutivo (el ceremonial de las cabañas o enramadas en el campo).

127 Ibidem. No consta su valor de predicción.

128 Alvar, Léxico, p. 448 (n. 84).

129 Manuel TOHARIA, Meteorología popular (Madrid: El Observatorio Ediciones, 1985), pp. 51-52.

130 TOHARIA, Meteorología, p. 51 (n. 129).

131 Sukkot en hebreo (véase la Encyclopaedia Judaica, s.v. Sukkot) [n.100]. 


\begin{abstract}
Cabañuelas. usado en plurál. La fiesta que hacian los Judíos en un lugar ò arrabál de Toledo, llamado Cabañuelas, dicha de los Tabernáculos, que afirma Covarr. era la de la Scenopegia, para cuya celebridad hacian ciertas cabañas ò enramadas en el campo por espacio de quarenta dias, en memória de los quarenta años que anduvieron peregrinando por el desierto antes de entrar en la tierra de Promissión. Es voz Toledana $[\ldots]$

Cabañuelas. Se toma tambien por la vana observación que hacen algunos de los doce priméros dias del mes de Enéro, infiriendo de cada uno de ellos por su orden el tiempo que hará en los doce meses del año ${ }^{132}$.
\end{abstract}

La última edición del diccionario académico ${ }^{133}$ recoge la segunda acepción de cabañuelas (ampliada y remodelada), tal como he reproducido más arriba (apartado 3, nota 20), y remite la fiesta de las cabañuelas (s.v. cabañuela) al artículo fiesta: // de las cabañuelas, o de los tabernáculos.

En cuanto a las caban(y)elles del catalán, formación derivada con otro sufijo diminutivo (del lat. -ELLAS), el DCVB registra ambas variantes fonéticas (con - $n$ - y con - $n y$-) ${ }^{134}$; ambas con la acepción de 'la fiesta de los Tabernáculos', sin referencia alguna al método de predicción anual. Cabanelles, con la notación de antigua; no así cabanyelles. La misma obra de Alcover y Moll ${ }^{135}$ incluye además una Pasqua de les cabanyes, en referencia también a la fiesta judía (véase ahora mi nota 101).

Las cabanyoles/cabanyueles atestiguadas en la provincia de Alicante ${ }^{136}$ me dan toda la apariencia de ser adaptadas del castellano. ¿Al rescoldo acaso de las inmediatas cabañuelas de Murcia? Cf. para unas y otras 3.3,a).

\title{
4.3. DENOMINACIONES DIVERSAS
}

\section{3,a) El calendario (no derivado patrimonial de CALENDAS, sino cultismo)}

- hacer el calendario: provincia de Salamanca ${ }^{137}$.

- el calendario (Soria), denominación alternativa a los doce días; cf. $3.1, \mathrm{~g})$ y $4.3, \mathrm{~b})$.

- calendario (Romagna); cf. 3.2,b).

132 Diccionario de Autoridades, s.v. cabañuela (n. 74).

133 DRAE (1992, 21." ed.) [n. 20].

${ }_{134} D C V B$ (n. 18). Véase también, para estas variantes formales, el DECat, s.v. cabanya o cabana (n. 58).

135 DCVB, s.v. cabanya (n. 18).

136 Por RAMÓN MORTE, Clima y tradición oral, pp. 199-200 (n. 108).

137 Blanco, El tiempo, p. 60 (n. 109); no se especifican las correspondencias entre días y meses. 


\section{3,b) Los doce días}

- los doce días (Soria), denominación alternativa a calendario; cf. 3.1,g) y $4.3, \mathrm{a})$.

- los doce dias: provincia de Salamanca ${ }^{138}$.

\section{3,c) Derivados de COMPUTARE}

- li coumtié ('los contados'); en referencia seguramente al concepto 'días' (en provenzal antiguo); cf. 3.1,a).

- jours compteurs (Provenza; ¿francés regional?); cf. 3.1,a).

- yúorne kuntáte: Calabria; cf. 3.1,a).

- compte del Rei Salomó: Mallorca; cf. 3.1,f).

- compte de Salomó: Mallorca; cf. 3.3,h).

\section{3,d) Signos}

- signos: Huerta Oscense; y castellanismo del catalán (cf. 3.1,e).

- signes del cel (signes dobles): en catalán; cf. 3.1,e).

\section{3,e) Témporas}

Tipo léxico, éste, derivado del lat. TEMPus, y vinculado semánticamente a la renovación temporal, de las cuatro estaciones del año y su respectivo comienzo ${ }^{139}$. Por lo que no sorprende su acomodo a significar nuestro método de predicción, que inicia y renueva el año.

- témporas: Lage, Coruña ${ }^{140}$.

138 Ibidem. Sin especificación de correspondencias entre días y meses.

139 Cf. la definición del DRAE, s.v. témpora (n. 20): 'Tiempo de ayuno en el comienzo de cada una de las cuatro estaciones del año'.

140 Alvar, Léxico, p. 448 (n. 84). Sin especificación de correspondencias entre días y meses. Léase además al respecto el artículo témporas del diccionario de la Real Academia Galega (n. 75), y especialmente las alusiones a la predicción popular del tiempo, para cada estación o para todo el año.

Témporas. s.f.pl. Cada unha das estacións do ano e comezo delas [...] queda-las témporas de arriba ou de abaixo: Expresión utilizada para sinala-lo lugar de onde 
- as têmporas: al norte de Portugal (cf. 3.1,j); para las denominaciones alternativas o complementarias de arremessas, arremedas, (des)arremedares, cf. $4.3, \mathrm{~h})$ y 4.4 .

- têmporas de Santa Luzia: entre el Duero y el Miño ${ }^{141}$.

- témpores // témpores del moro: Mallorca; cf. 3.1,k).

\section{$4.3, f) \quad$ Suertes}

- jours de sort: en algunas regiones de Francia, en Bélgica.

- jours des lots: en los Vosgos; para este testimonio y el anterior véase 3.1 (c).

- Lostage (y variantes): denominación en lengua alemana atribuida a la Suiza germánica; cf. 3.1,c).

- sortes // resortes: en Galicia; cf. 3.2,b) y f).

\section{$4.3, \mathrm{~g})$ Canículas}

Supongo que por transcurrir la predicción durante la temporada canicular.

- canículas: en puntos de Castilla y León (sin especificar) ${ }^{142}$; en la provincia de Salamanca (cf. 3.3,f); en la localidad oscense de Castillazuelo ${ }^{143}$.

vén o aire (norte, sur, etc.), o día en que entra cada unha das estacións do ano ou outros días, feito que, segundo a crenza popular, determina que de alí vai sopra-la maioría dos días da estación que comeza, condicionando, por conseguinte, o tempo que vai facer durante os tres meses que dura aquela ou incluso todo o ano.

141 CÂmara, Dicionário, s.v. chuva (n. 35). Sin especificación de correspondencias, por más que el añadido de Santa Luzia apunta a que se comience el recuento desde el 13 de diciembre. Remite el autor a cierta fuente: "Joaquim PIRES DE LIMA, Tradições Populares de Entre-Douro-e-Minho, 73, colaboração com o Dr. Fernando Pires de Lima, Barcelos, 1938".

142 Carril Ramos, "Etnometeorología", p. 127 (n. 57).

143 BARRABÉs et alii, "Las calandras", p. 219 (en la nota 15 de la obra citada) [n. 42 de mi artículo]. Sin correspondencias explícitas entre días y meses. 


\section{3,h) Otros nombres (por orden aproximativamente alfabético)}

- Las arremessas [sic] atestiguadas como denominación alternativa a têmporas (cf. 4.3,e) en la región portuguesa del Miño ${ }^{144}$, se habrán de identificar con las arremedas de entre Miño y Duero. Como los arremedares de la misma región. Todas estas variantes (cf. 3.1,j) formarían parte de la familia léxica de arremedar, en su acepción de 'anunciar'. Infinitivo substantivado (en forma de masculino y plural) son los arremedares. Derivado postverbal de arremedar parecen las arremedas. Acaso deturpación de éstas, las arremessas. Para el desglose de los arremedares (m.pl.) en arremedar (docena de ida) y desarremedar (docena de vuelta), cf. 4.4.

- cabichuelas: en algunos lugares de Castilla y León ${ }^{145}$; en la provincia de Salamanca (cf. 3.3,c). Parece deformación de cabañuelas.

- as canablas: Escapa, Alto Aragón (cf. 3.1,e). Me pregunto si serán deformación de calandras, atraídas formalmente por canabla(s) ('collar del cencerro de una res'), variante (continuadora del lat. CanNabula) bien representada en el Alto Aragón ${ }^{146}$.

- experiências de Santa Luzia: Ceará, Brasil. "Experiencias" en el sentido de 'pruebas', 'indicios', 'experimentos'. A contar desde el día de la Santa (cf. 3.1,b). También se denomina (en singular) experiência de Santa Luzia el indicio material que se observa en esa misma parte de Brasil, y que describo en el apartado 5.

- bilegunak ('días de meses'): en el vasco de Vizcaya; cf. 3.3,g).

- Derivados de INDICARE: endegaro (en singular) / endegari (en plural); zorni endegari (con el substantivo zorni 'días' explícito); en el Véneto (cf. $3.2, \mathrm{~g}$ ).

- jours mâles: en el francés de algunas regiones (cf. 3.1,c); desconozco la motivación de tales 'días machos' [?].

- pintas: Costa Rica (cf. 3.2,c). Con el verbo pintar se refieren allí mismo al gobernar de los días sobre los meses correspondientes ${ }^{147}$.

144 Testimonio de CunHA, "Etnografia", p. 307 (n. 60)

145 CARril RAMOS, "Etnometeorología", p. 127 (n. 57).

146 Manuel Alvar con la colaboración de Tomás BUESA, Antonio Llorente y Elena Alvar, Atlas lingüístico $y$ etnográfico de Aragón, Navarra y Rioja (Zaragoza/Madrid: Departamento de Geografía Lingüística / Institución “Fernando el Católico" / Diputación Provincial de Zaragoza / CSIC, 1979-1983, 12 vols.), mapa 555-COLLAR DEL CENCERRO. El DRAE (n. 20) recoge asimismo la variante canaula, con la localización de aragonesa.

147 Cf. la duodécima acepción del $D R A E$ (n. 20) para pintar (fig. fam.): 'Empezar a mostrarse la cantidad buena o mala de una cosa'. 
- polas: en la parroquia viguesa de San Andrés de Comesaña, Galicia (cf. 3.2,e); complementadas con una docena doble de repolas (4.4). Pronunciadas, éstas y aquéllas, con "O" cerrada según mi informante, natural de San Andrés. Ignoro si tendrán que ver tales (re)polas con la póla ('rama', con "O" abierta) o con la pola ('polla, gallina joven', con "O" cerrada) del gallego.

- pornostico [sic], variante popular de pronóstico (Alto Aragón); cf. $3.1, \mathrm{e})$.

- al spèi dl an ('los espías del año'): Castel Bolognese, EmiliaRomagna; cf. 3.2,d).

- tretzenades (de devant // de recules): Rossell, Castellón; tretzenaes // - de recules: la Fresneda, Teruel; tretzenaes: Benassal, Castellón. Las tres poblaciones, catalanohablantes. ¿Responderá tretzena(d)es a que se inicia el cómputo por el trece de diciembre? ${ }^{148}$ Cf. 3.1,e) y $3.1, j$ ).

- zotal-egunak ('días augurales'): en el vasco de Navarra, Lapurdi y Zuberoa; cf. 3.2,b).

\subsection{APÉNDICE: DOBLES DOCENAS, DOCENAS REPETIDAS}

- Por medio de derivados (con prefijo o sufijo): calendas // recalendas (3.1,e y 4.1); sortes // resortes (3.2,b y f); polas // repolas (3.2,e y 4.3,h); caländ // descaländ (4.1); arremedar // desarremedar (3.1,j y 4.3,h); calendre // scalendre (3.2,f y 4.1); càlenni // calindèn (3.2,h y 4.1).

- Por medio de recursos sintácticos (con especificación léxica): calandras de retaculas (3.1,e); tretzena(d)es (de devant) // de recules $(3.1, \mathrm{e}$ y $3.1, \mathrm{j})$; cabañuelas de ida // de retorno; (-) // los (dias) retorneros; (cabañuelas) retorneras (todo ello en 3.3,a); cabañuelas grandes // chiquitas (3.2 (d)); signes del cel (signes dobles) (3.1,e); (-) // témpores del moro $(3.1, \mathrm{k})$.

- Por diferenciación léxica: anaes // retornaes $(3.3, a)$.

${ }_{148}$ En alguna otra ocasión me he referido ya a esa posibilidad: Gargallo / Pradilla, El joc ancestral, pp. 53-54 (n. 51); José Enrique Gargallo GIL, "Santa Lucia, la notte più lunga che ci sia: el calendario de refranes (en torno al solsticio de invierno) y la serie romance de Santa Lucía", (Giovanni RuFINO, ed.) Atti del XXI Congresso Internazionale di Linguistica e Filologia Romanza. Centro di studi filologici e linguistici siciliani / Università di Palermo (18-24 settembre 1995) (Tübingen: Max Niemeyer Verlag, 1998), V, pp. 357-366 (y concretamente las pp. 360-361). 


\section{DOCE INDICIOS MATERIALES, Y UNA NOCHE}

On place en ligne douze oignons creusés en forme de coquilles de noix, et celà dès le 25 décembre [...]

Dans chaque oignon ainsi creusé, on met une pincée de sel. Le premier, en començant par la gauche, correspond au mois de janvier et les autres aux mois suivants d'après leur rang.

Au jour des Rois, qui est le dernier des jours des lots, on examine les oignons. Là où le sel n'est pas fondu, le mois correspondant doît être sec; là où il est fondu, le mois correspondant doît être humide ${ }^{149}$.

Doce indicios materiales acompañan a los doce días, en la predicción de otros tantos meses, según se detalla en la cita. Doce cebollas vaciadas en forma de cáscaras de nuez, y un pizco de sal en cada una, apuntan la suerte de cada mes, a lo largo de esos doce jours des lots. Si la sal depositada en cada trozo se mantiene sólida, augura un mes seco. Si se disuelve y hace agua, uno húmedo o lluvioso. Semejante pronóstico de doce indicios materiales para doce meses se practica en otros lugares romances, según acreditan otras tantas fuentes. Pero concentrado en el espacio de una noche, de un día para el si-guiente ${ }^{150}$.

Doce mitades, doce cascos o capas de cebolla. En algún caso doce medias cáscaras de nuez. Y los correspondientes pizcos de sal. O doce

149 Proverbes, p. 118 (n. 31), que localiza esta práctica en los Vosgos.

150 Pronóstico que, en diversas variantes materiales, con diversa ejecución, es seguramente conocido y practicado desde antiguo. Y no sólo en el mundo romance.

Dans plusieurs pays de la Méditerranée, où l'absence d'eau se fait souvent cruelment sentir, on mesure l'humidité à l'aide de pelures d'oignons ou de feuilles de figuier. (Sike, Fêtes et croyances, p. 46 [n. 5])

Pieles o trozos de cebolla, como los doce que, según esta misma autora, acogen en Nochebuena la sal que revelará al día siguiente la pluviosidad de los doce meses por venir. Una de las variantes con mayor refrendo entre mis testimonios románicos de este punto. Afín al "Oráculo de las cebollas" (Zwiebelorakel, en alemán, y denominaciones populares semejantes en suizo-alemán) que HAUSER (Bauernregeln [n. 39]) acredita, aquí y allá, en la Suiza de habla alemana: de la Nochebuena a la Navidad (pp. 65-66, 181-182), y también de la Nochevieja al Año Nuevo (p. 186).

Hojas de higuera, como las doce que, según esta última fuente, acogían un oráculo similar en la antigua Grecia.

Im alten Griechenland wurden bei Siriusaufgang die Namen der zwölf Monate auf Feigenblätter geschrieben. Diese legte man in der Nacht ins Freie. Das Blatt, das am andern Morgen feucht war, zeigte an, daß der entsprechende Monat schlechtes Wetter haben werde [...] (HAUSER, op. cit., p. 65) 
montoncitos de sal, sin más. Materia prima imprescindible, la sal. De evocaciones bíblicas, de ancestral provecho.

Docenas materiales, en cualquier caso, a las que se asignan doce correspondencias mensuales en la vigilia de cierto día. Transcurrida la noche, el día siguiente revelará los augurios para cada mes. Lluvioso o húmedo, si la sal respectiva se ha hecho agua. Seco, si sigue seca su sal.

En Xerta ${ }^{151}$ se tenía por costumbre partir los doce trozos de cebolla coincidiendo con las doce campanadas de fin de año. $\mathrm{Y}$ a tal práctica responde la denominación de calendari ceboller en esta localidad catalana, así como el refrán: Ceba de Cap d'any / fa bon averany ${ }^{152}$.

Calendari de la ceba, según otro testimonio catalán ${ }^{153}$, que nos habla de 12 clofolles de ceba (capas de cebolla) dispuestas junto al fuego del hogar en la vigilia del Año Nuevo o en la de Navidad.

Calendario de la Seba (con tal grafía) le atribuye cierto autor (aragonés) ${ }^{154}$ al territorio fronterizo de la Ribagorza. Y especifica que el primer día del año ponen ante las brasas del hogar doce cascos de cebolla, con los pertinentes pizcos de sal, y esperan su resultado (pero no precisa si tras una noche de espera; ni, si es así, tras cuál).

Sí que identifican esa noche augural otras fuentes. Así, la Nochebuena de la región del Miño ${ }^{155}$, o la Nochevieja altoaragonesa ${ }^{156}$. Asimismo en Nochevieja disponen sus capas de cebolla en Areny (Huesca), en el Aragón fronterizo de lengua catalana ${ }^{157}$. En la víspera del Año Nuevo también, dejan al sereno doce granos de sai, en Puerto Rico, para observar al día siguiente las doce suertes de cada mes ${ }^{158}$.

Doce mitades de cebolla, con la sal respectiva, se preparan antes de la Misa del Gallo, y a la vuelta, aún de noche, se observa el resultado de cada pieza ${ }^{159}$.

151 Según el testimonio, ya lejano, de Gomis, Meteorología, p. 101 (n. 34).

152 Ibidem.

153 Amades, Costumari, II (1989), pp. 14-15 (n. 50).

154 ANDOLZ, Los aragoneses, p. 34 (en la nota 15) [n. 44].

155 Según el testimonio portugués de CunHA, "Etnografia", p. 308 (n. 60).

156 Por lo que se lee en un calendario del Consello d'a Fabla Aragonesa para el año 1998.

157 BARRABÉs et alii, "Las calandras", p. 212 (n. 42).

158 CÂmARA, Dicionário, s.v. chuva (n. 35). Aporta una detallada cita de María CADILla DE MARTÍNEZ, Costumbres y tradicionalismos de mi tierra (Puerto Rico, 1938).

159 Así se indica en la obra divulgativa de Manuel TOHARIA, Meteorología popular, p. 60 (n. 129). Si bien no aporta localización, parece que la costumbre se haya de atribuir a algún lugar del ámbito hispánico (pues hispánico es el ámbito lector al que se dirige el autor en el tono de su obra). 
Otra fecha solsticial, en el inicio del verano, es la elegida en tierras de Alicante ${ }^{160}$. Y doce cascos de cebolla, los observados, de la víspera de San Juan para el día siguiente.

El 25 de enero, el día en que se confirman o desmienten los vaticinios de las dos docenas de días previos $(3.2, \mathrm{~g})$, es la jornada para la que se reservan los augurios materiales propios de Verona ${ }^{161}$. Doce capas de cebolla (tuniche di cipolla), o a veces 12 medias cáscaras de nuez, y siempre los correspondientes pizcos de sal, materializan aquí la predicción, que recibe el significativo nombre de calèndre (cf. 4.1,a).

Doce montoncitos de sal sobre una mesa y al amor de la lumbre en Beja (Portugal), por San Juan ${ }^{162}$.

Media docena de piedras de sal se depositan sobre un llano la víspera del 13 de diciembre (Santa Lucía), y revelan al día siguiente el tiempo de seis meses de un invierno brasileño ${ }^{163}$, en Ceará. Reveladora experiência de Santa Luzia ${ }^{164}$.

Doce santalucias ${ }^{165}$ es costumbre reunir en Costa Rica por diciembre. Doce augurios que se creen portadores de fortuna de cara al año por venir. Doce flores de las que, según me han contado en esa parte de mundo, cada cual se reserva al menos una, y obsequia las restantes como prenda de afecto y amistad.

160 RAMÓN MORTE, Clima y tradición, p. 200 (n. 108).

161 RAMA, Proverbi, p. 100 (n. 90).

162 BRAGA, O povo portuguez, II, p. 322 (n. 35). No especifica el autor si la vigilia o el día 24 de junio.

163 Otro "invierno", el de Ceará, distinto del europeo. Época de lluvias, de enero a junio, como ya he dejado dicho (3.1 (b) y la nota 35).

164 Véanse otros detalles en BRAGA, O povo portuguez, II, p. 322 (n. 35); y CÂMARA, Dicionário, s.v. chuva (n. 35).

165 Así escrita, en una sola palabra de molde compuesto, esta santalucia. Deonomástico procedente de Santa Lucia. Debe su nombre a la época de floración de las santalucias, en torno al 13 de diciembre.

santalucia f. Nombre de mala hierba que florece al principio de la época seca (diciembre), de flores lilas y azuladas (Ageratum conyzoides). Es costumbre en ciertos lugares recortar doce de esas florecillas para tener consigo a la entrada del año nuevo. [Miguel Ángel Quesada PACHeco, Nuevo diccionario de costarriqueñismos (Cartago: Editorial Tecnológica de Costa Rica, 1991), s.v. santalucia]. 
Una de las manifestaciones perviventes del mythe de l'éternel retour (M. Eliade) es la previsión meteorológica que, en el renovarse de los años, representan doce días prefiguradores de otros tantos meses por venir. Práctica ancestral propia de distintas culturas, que este artículo aborda dentro de un marco romance (básicamente la Romania europea, con la salvedad del rumano). Buena parte de la aportación se dedica al catálogo de correspondencias entre días y meses así como a las denominaciones para los doce días de la predicción. Predicción que cabe vincular a los doce indicios materiales (sal, cebollas, nueces), cuyo comportamiento de cierto día para el siguiente observan en algunos lugares como revelador también de la suerte de doce meses.

One of the surviving manifestations of the mythe de l'éternel retour (M. Eliade) is the prediction concerning the weather expressed, as year succeeds to year, through the meteorological conditions of twelve days, which represent the twelve months to follow. This is an ancestral practice typical of a number of different cultures, but the present article will be limited to the Romance domain (basically the European Romance area, excluding Rumanian). Most of the contribution deals with the list of correspondences between days and months and also with the names assigned to the twelve days. This kind of prediction can be linked to twelve material indices (salt, onions, nuts), whose behaviour from one day to the next is considered in some places to be a premonition of what the future holds in store regarding the weather in the coming twelve months. 